\title{
FLORA BACTERIANA, SENSIBILIDAD ANTIBIÓTICA Y FACTORES ASOCIADOS EN ACNÉ VULGAR GRADO III Y IV HOSPITAL ANTONIO LORENA DEL CUSCO
}

\author{
Autores $\quad$ Dr. Roberto Amaru Zegarra ${ }^{I}$, Dr. Anibal Nieto Rueda ${ }^{I}$ \\ Coautores Dr. Luis Miranda Angeles ${ }^{2}$, Dra. Teresa Andía Salazar ${ }^{3}$
}

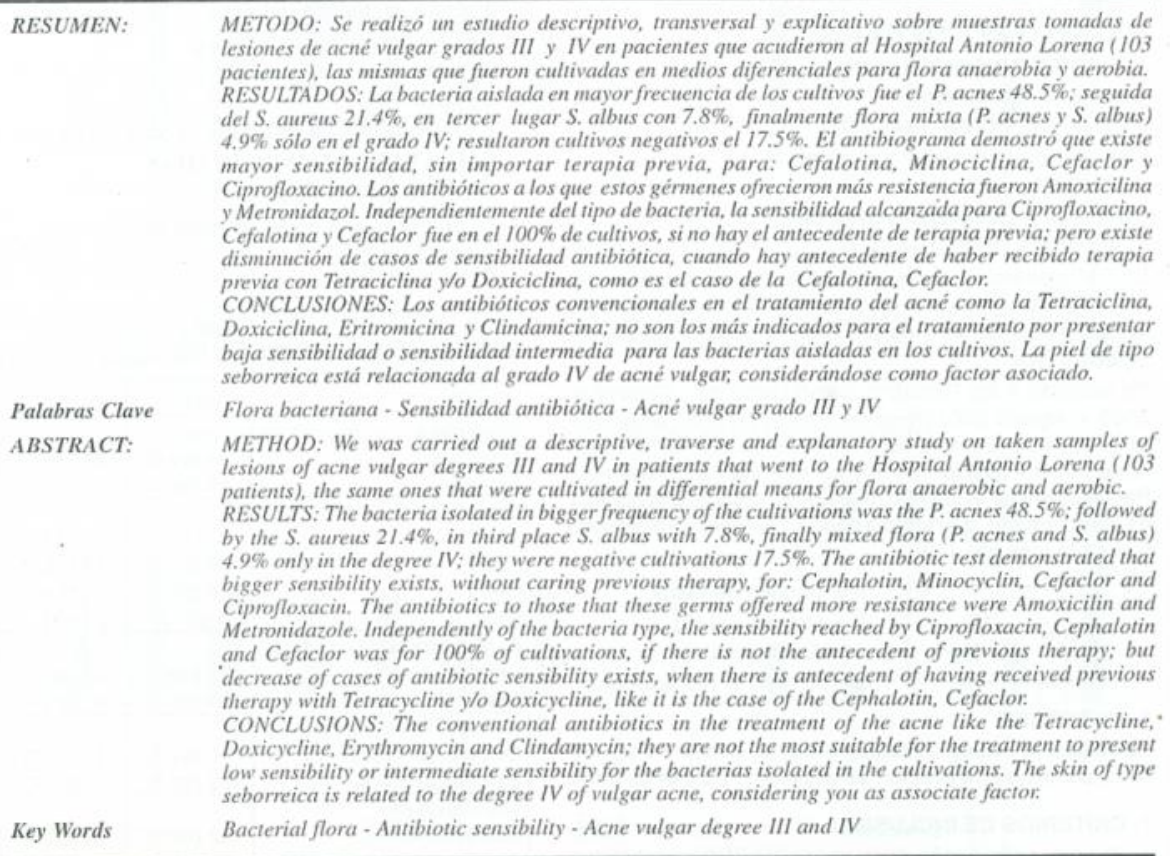

1 Médico egresado de la FMH UNSAAC, 2 Docente principal en la Cä́tedra de Infectología FMH-UNSAAC, 3 Dermatóloga del Hospital Antonio Lorena del Cusco 


\section{INTRODUCCION}

Si revisamos la literatura médica nos encontramos con que el ACNE VULGAR representa una de las afecciones sobre la que más se ha escrito, ya que es una patologia muy frecuente sobre todo en la adolescencia.

Es frecuente que las enfermedades de la piel se consideren triviales desde el punto de vista médico, ya que no implican una gravedad extrema en cuanto a su pronóstico. Pero, paradójicamente cobran una importancia muy signicativa en la esfera psicosocial del individuo. Tal puede ser el caso del ACNE VULGAR, debido a su impacto como enfermedad desfigurante.

El Acné vulgar grado III y IV, enfermedad frecuente en nuestro medio, ha sido tratado con antibioticoterapia, especialmente con las tetraciclinas, esto debido a que se sabe que la bacteria más común es el Propionibacterium acnes, y que ésta responde al tratamiento mencionado. En el Hospital Antonio Lorena del Cusco la experiencia en el Consultorio de Dermatologia ha demostrado que el tratamiento convencional antes mencionado no es el adecuado, y se ha sugerido que en nuestro medio la bacteria más común involucrada con Acné vulgar grado III y IV podría no estar sola, sino asociada a otras, debido a que cuando se usan antibióticos de otros géneros con actividad para otro tipo de gérmenes, los resultados han mejorado. Por todo lo expuesto la importancia de este trabajo radica en que al lograr nuevas alternativas de tratamiento en base a los resultados, lograremos un tratamiento mejor enfocado para el Acné severo, y así revalorar los tratamientos actuales que irán en beneficio directo de los pacientes.

\section{MATERIALES Y METODOS:}

1. TIPO DE INVESTIGACION

Científico - evaluativo

2. NIVEL DE INVESTIGACION

Descriptivo, transversal y explicativo.

3. DISEÑO

Diseño no experimental correlacional,

\section{SUJETOS DE ESTUDIO}

La población incluida en el estudio fueron pacientes con acné vulgar grado III y IV que acudieron al Consultorio Externo de Dermatología del Hospital Antonio Lorena del Cusco. 5. MUESTRA

De acuerdo a los Registros Estadisticos de Setiembre 2000 - Agosto 2001 (Hospital Antonio Lorena), acudieron al Consultorio Externo de Dermatología con lesiones de Acné severo (grado III y IV) un total de 138 pacientes. Para determinar el tamaño muestral se recurrió a la fórmula de Taro Yamane, que trabaja con una probabilidad del $50 \%$ que es la más alta (46).

$$
n=\frac{N}{1+\mathrm{Ne}^{2}}
$$

$\mathrm{n}=$ Tamaño muestral

$\mathrm{N}=$ Universo (138)

$\mathrm{e}=$ Error $(0,05)$

De donde $n=103$ pacientes

6. MUESTREO

Se realizó un muestreo sistemático, de donde $\mathrm{I}=2$ (uno de cada dos elementos fue seleccionado para el estudio)

\section{CRITERIOS DE INCLUSION}

1. Pacientes con Acné vulgar grados III y IV diagnosticados en el consultorio de Dermatología del Hospital Antonio Lorena del Cusco.
2. Autorización de los padres o el apoderado en caso de que existan pacientes menores de edad.

\section{CRITERIOS DE EXCLUSION}

1. Pacientes con otros tipos de acné que no sea el vulgar y con otros grados que no sean el III y IV.

2. Pacientes que recibieron tratamiento previo con antibióticos sistémicos y/o corticoides u otro medicamento tópico que puedan modificar las lesiones la presencia del agente causal, 7 días antes de tomarse la muestra.

3. Negación de padres o el apoderado en caso de que el paciente sea menor de edad.

4. Pacientes con el diagnóstico de Acné Vulgar grados III y IV que presentaron piodermitis asociadas, enfermedades sistémicas asociadas, infecciones en uno o más órganos o sistemas del organismo, e inmunodeficiencia de cualquier etiologia.

Para la selección de los pacientes de acuerdo a los criterios de inclusión y exclusión se contó con el diagnóstico del experto (Dermatóloga del Hospital Antonio Lorena).

9. ASPECTOS ETICOS

Para el presente trabajo se pidió la autorización por escrito de cada paciente, indicándole los procedimientos a los que se sometió, proporcionándole la información adecuada acerca de la investigación y el propósito de realizarla, de acuerdo a la Declaración de Helsinki (29).

VARIABLES IMPLICADAS

1. Acné vulgar grado III y IV.

2. Sensibilidad antibiótica.

3. Flora bacteriana del acné.

4. Caracteristicas de la piel.

5. Edad.

6. Sexo.

7. Antecedentes de los padres de acné vulgar grados III o IV. VARIABLES NO IMPLICADAS

INTERVINIENTES DEL SUJETO

1. Antecedentes de tratamiento antibiótico.

\section{RESULTADOS}

Cuadro 1

CARACTERISTICAS DE LAS VARIABLES EN EL ESTUDIO

\begin{tabular}{|l|l|l|r|}
\hline Variable & \multicolumn{1}{|c|}{ Grado III } & \multicolumn{1}{|c|}{ Grado IV } & Valores P \\
\hline Sexo (\%) & & & 0.90 \\
Masculino & $54(69.2)$ & $24(30.8)$ & \\
Femenino & $17(68)$ & $8(32)$ & \\
\hline Edad (\%) & & & 0.10 \\
$12-17$ & $8(11.3)$ & $4(12.5)$ & \\
$18-23$ & $45(63.4)$ & $19(54.4)$ & \\
$24-29$ & $18(25.4)$ & $7(21.9)$ & \\
$>30$ & $0(0)$ & $2(6.3)$ & \\
\hline Caracteristicas de la piel (\%) & & & 0.004 \\
Seborreica & $42(60)$ & $28(40)$ & \\
Mixta & $29(87.9)$ & $4(12.1)$ & \\
\hline Anteced. Familiares (\%) & & & 0.20 \\
Con antecedentes & $16(59.3)$ & $11(40.7)$ & \\
Sin antecedentes & $55(72.4)$ & $21(27.6)$ & \\
\hline Tto. Previo (\%) & & & 0.13 \\
Con Tto. & $42(63.6)$ & $24(36.4)$ & \\
Sin Tto. & $29(78.4)$ & $8(21.6)$ & \\
\hline
\end{tabular}


Gräfico

Comparación Porcentualentre Bacteria Aislada y Grado de Acné

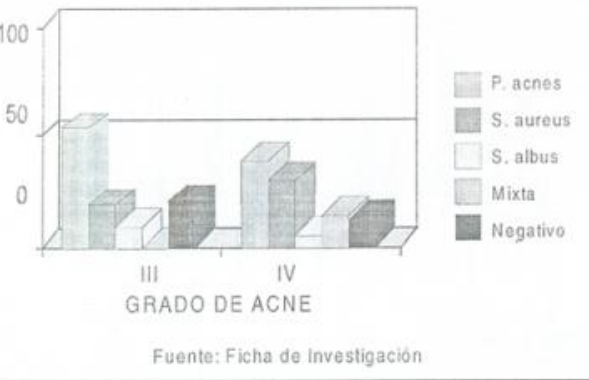

La bacteria más frecuente en ambos grados de acné fue el P. acnes. Sólo se observó flora mixta en el grado IV.
Gráfico 2

Distribución de las caracteristias de la piel segun Grados de Acne

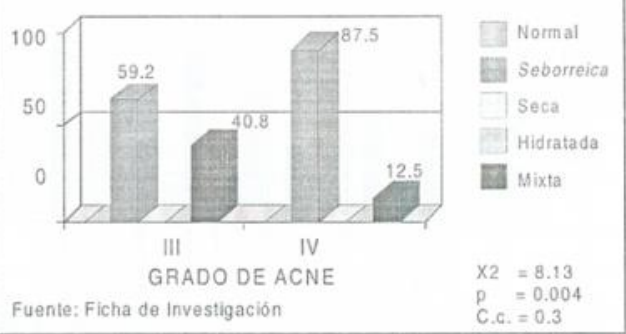

La piel tipo seborreica tuvo un alto porcentaje en ambos grados de acné, teniendo relación significativamente estadistica con el grado IV de acné vulgar.

También se determinó la piel tipo mixta en menores porcentajes, no asi los otros tipos de piel que no se lograron determinar.

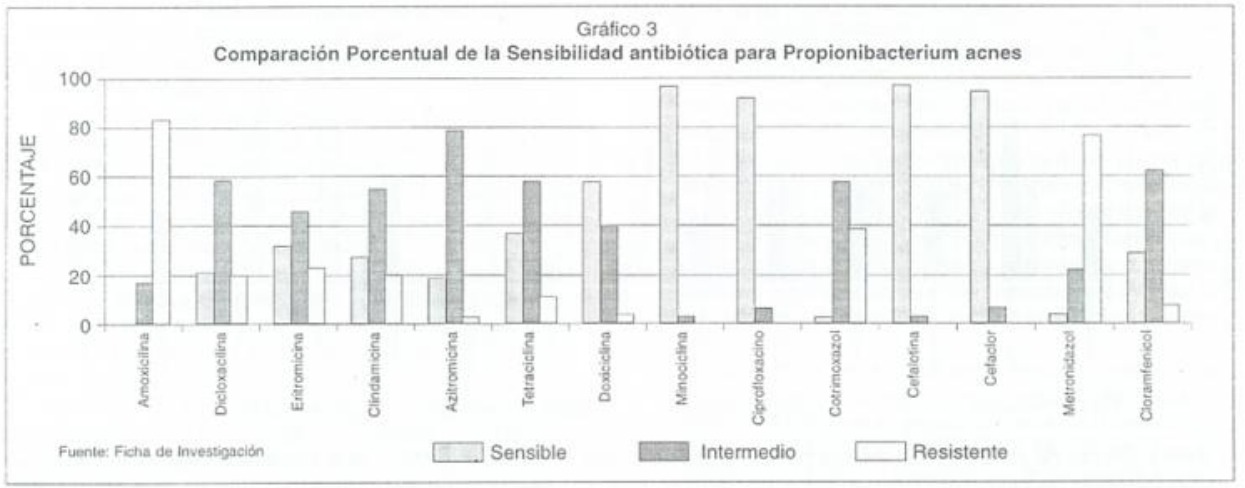

P. acnes resultó ser muy sensible a la Cefalotina y Minociclina (96,4\%), junto con Ciprofloxacino y Cefaclor $(92,7 \%)$. Grado intermedio más alto $(78,2 \%)$ para Azitromicina. Mayor resistencia para Amoxicilina $(85,5 \%)$ y Metronidazol $(74,5 \%)$.

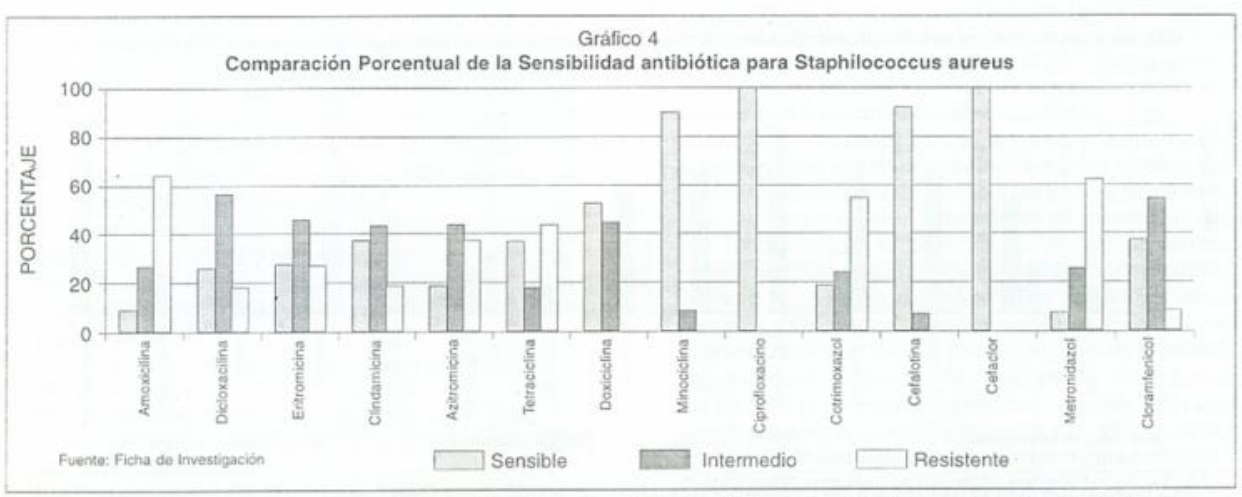

S. aureus presentó mayor sensibilidad para Ciprofloxacino, Cefaclor $(100 \%)$. Grado Intermedio más alto $(54,5 \%)$ para Dicloxacilina y Cloramfenicol. Mayor resistencia para Amoxicilina y Metronidazol $(63,6 \%)$. 


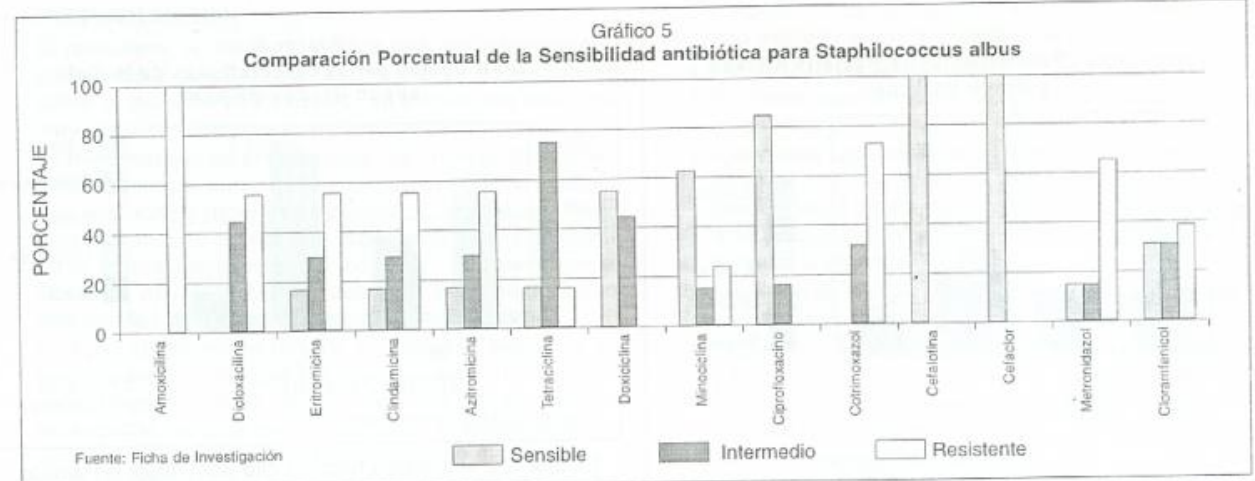

S. albus resultó ser más sensible a Cefalotina y Cefaclor (100\%). La resistencia más alta fue para Amoxicilina (100\%), mientras que presentó sensibilidad intermedia más alta a la Tetraciclina $(69,2 \%)$.

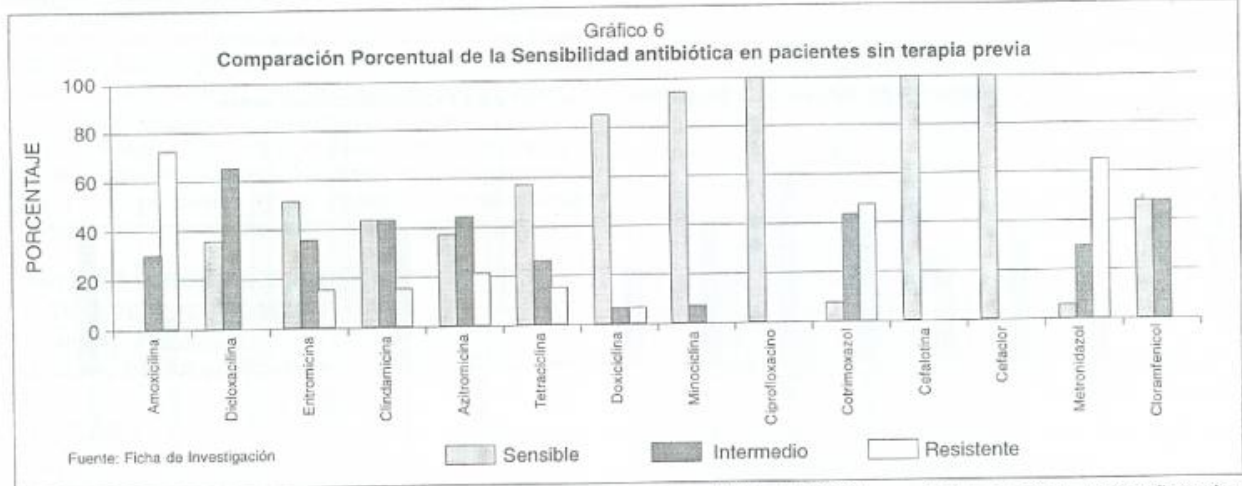

La flora aislada de pacientes sin terapia previa, presentó mayor sensibilidad $(100 \%)$ para Cefalosporinas y Ciprofloxacin (en la totalidad de cultivos). Grado intermedio más alto para Dicloxacilina $(64,3 \%)$. Grado de resistencia más alto para Amoxicilina $(71,4 \%)$.

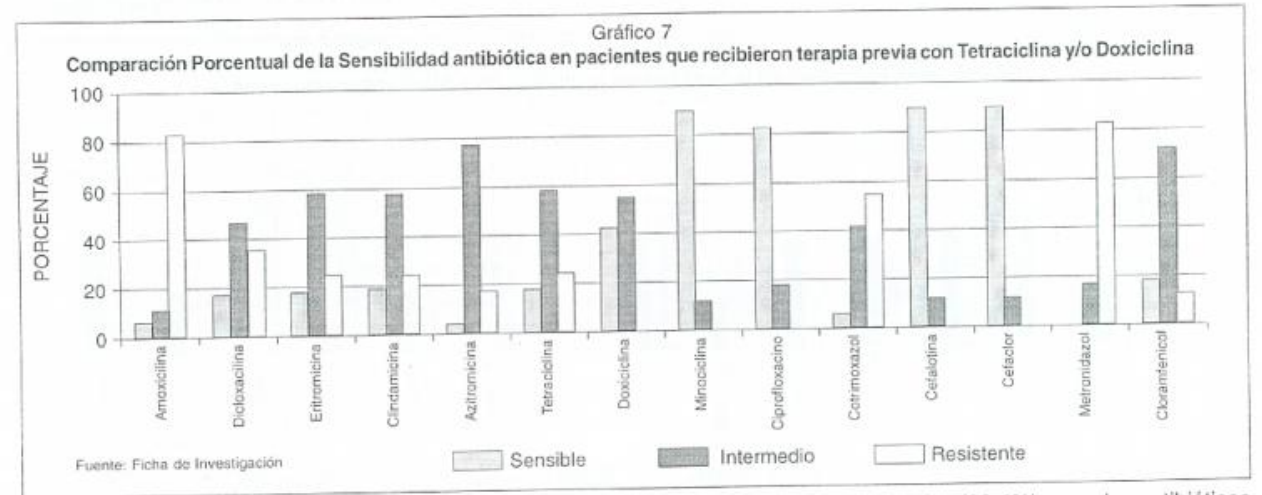

a flora hallada fue más sensible para las Cefalosporinas, Minociclina ( $88.2 \%$ ) y Ciprofloxacino ( $82.4 \%$ ); para los antibióticos convencionales (Tetraciclina, Eritromicina, Clindamicina y Doxiciclina) presentaron sensibilidad intermedia que no superan el $60 \%$. Mayor resistencia fue hallada para Amoxicilina y Cloramfenicol. 
Gráfico 8

Comparación Porcentual de la Sensibilidad antibiótica en pacientes que recibieron terapia previa con Tetraciclina y/o Doxiciclina con Eritromicina

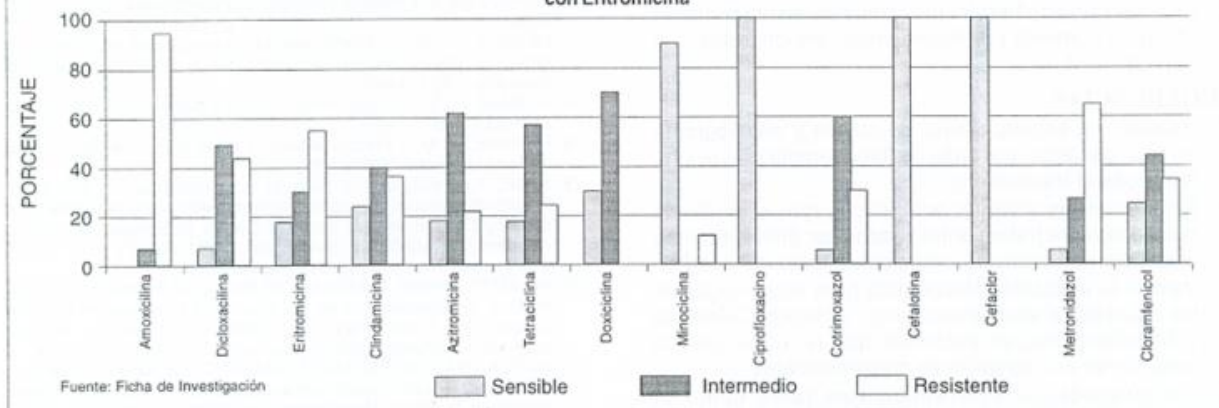

La flora encontrada fue más sensible para Cefalosporinas y Ciprofloxacino en todos los cultivos de lesiones de pacientes que recibieron terapia previa (100\%). Los antibióticos convencionales (Eritromicina, Clindamicina, Tetraciclina y Doxiciclina) no superan el $31 \%$. Mayor resistencia se observó para Amoxicilina $(91,3 \%)$. Sensibilidad intermedia más alta para Doxiciclina $(69,6 \%)$.

\section{CONCLUSIONES}

1. EI P. acnes fue la bacteria preponderante en ambos grados de acné concordante a la literatura médica.

2. La flora mixta solamente se encontró en el grado IV ( $P$. acnes y $\mathrm{S}$. albus).

3. Se demostró que los antibióticos con mayor sensibilidad (según antibiograma) para P. acnes, S. aureus y S. albus, sin importar terapia previa, fueron: Cefalotina, Minociclina, Cefaclor y Ciprofloxacino. Los antibióticos a los que estos gérmenes ofrecen más resistencia fueron Amoxicilina y Metronidazol.

4. Independientemente del tipo de bacteria, la sensibilidad alcanzada para Ciprofloxacino, Cefalotina y Cefaclor fue del $100 \%$ de cultivos, si no hay el antecedente de terapia previa; pero existe disminución de bacterias sensibles, cuando hay antecedente de haber recibido terapia previa con Tetraciclina y/o Doxiciclina, como es el caso para la Cefalotina, Cefaclor (disminuye a $88.2 \%$ ) y Ciprofloxacino a $82.4 \%$.

5. Se concluye que la Tetraciclina, Doxiciclina, Eritromicina y Clindamicina; indicados entre otros para la terapia contra acné según la literatura dermatológica, no son los más indicados para el tratamiento por presentar bajos porcentajes de sensibilidad o sensibilidad intermedia para las bacterias aisladas en los cultivos; no así los medicamentos alternativos considerados en nuestras hipótesis como Cefalotina, Cefaclor y Ciprofloxacino que llegan a tener sensibilidad para el $100 \%$ de cultivos de S. aureus y S. albus.

6. No se encontró relación estadisticamente significativa entre el género y el grado de acné.

7. Se observó mayor frecuencia de casos en el grupo etáreo de $18-23$ años en ambos grado de acné, con disminución a medida que aumentaba la edad, pero sin relación significativamente estadistica entre la edad y grado de acné.

8. La piel de tipo seborreica está relacionada al grado IV de acné vulgar $(87.5 \%$, y un valor de $p<0.05)$, considerándose como factor asociado; en el grado III, no hay diferencias estadisticamente significativas entre piel mixta y seborreica.

9. No se evidenció relación entre los antecedentes familiares (del padre y/o madre) y el grado de acné, no encontrándose predisposición familiar en la severidad de la enfermedad.

\section{DISCUSION Y COMENTARIOS}

1. En relación al sexo, se observó la predominancia de género masculino sobre el femenino en una relación proporcional de $3: 1$; según la literatura médica, hay mayor predisposición para el acné vulgar en el sexo masculino que en el femenino.

2. El antecedente de haber recibido terapia previa con Tetraciclina - Eritromicina, Doxiciclina - Eritromicina, o la combinación de los tres; no disminuye el porcentaje de cultivos sensibles para Ciprofloxacino, Cefalotina y Cefacior, pero sí para los demás antibióticos; en contraposición a resultados de otros estudios que indican un pumento resistencia bacteriana si existe tratamiento previo.

3. La Minociclina es el único antibiótico del grupo de las Tetraciclinas que presenta mejor sensibilidad para los cultivos $(92.9 \%)$ en el grupo que no recibió tratamiento previo, mientras que disminuye a $88.2 \%$ en el grupo de terapia previa con Doxiciclina y/o Tetraciclina, y aún más sise utilizó también Eritromicina en que desciende a $87 \%$. Estudios como el de Kurukawa y colab. no a $87 \%$. Estudios como el de Kurukawa y colab. no
muestran resistencia de P. acnes para Minociclina (21).

4. Antibióticos convencionales para terapia como: Eritromicina, Clindamicina, Tetraciclina y Doxiciclina presentan una sensibilidad menor al $86 \%$ de los casos, presentan una ser prercentaje que disminuye sithubo terapia previa en rangos que fluctúan entre $47.1 \%$ y $17.6 \%$.

5. Tetraciclina, Eritromicina, Clindamicina y Azitromicina presentan una resistencia de por lo menos $14 \%$ de los cultivos en pacientes sin tratamiento previo, porcentaje que aumenta si existe el antecedente de terapia anterior con Tetraciclina y/o Eritromicina y/o Doxiciclina, siendo

la Eritromicina, alcanzando un $52 \%$ recientes (30), presenta cultivos sensibles en $35,7 \%$ en el grupo $\sin$ terapia previa, disminuyendo más si recibió terapia previa oscilando valores entre $17,4 \%$ y $5,9 \%$.

7. La terapia previa del paciente no guarda relación significativa en la severidad del acné, por consiguiente, no influiria en la progresión de la enfermedad contrariamente a los resultados de otros estudios $(19,11,31)$. mente a los resultados de otros estudios $(19,11,31)$. el mínimo lapso fue de 1 semana y el máximo intervalo 
de tiempo de 10 semanas, con un promedio de 4 - tiempo de 10 semanas, con semanas; estudios previos con tratamiento por corto tiempo y aumenta por tratamientos prolongados ( 2 a 6 meses) $(11,19)$.

\section{SUGERENCIAS}

1. Realizar un estudio previo de cultivo y antibiograma en todo paciente que halla recibido terapia previa y no responda al tratamiento.

- No indicar los mismos antibióticos que el paciente re ante falta de respuesta o empeoramiento del cuadro.

3. Valorar la indicación terapéutica para acné vulgar de los antibióticos alternativos como: Cefaclor, Cefalotin los antibioticos altemativos com que no respondan a y Ciprofloxacino, entibióticos convencionales.

4. Los antibióticos convencionales tales como la Doxiciclina, Tetraciclina, Eritromicina y Clindamicina Doxiciclina, Tetracićn a de las podrian seguir usanatos para el tratamiento de acné, por su sensibilidad intermedia.

5. Realizar estudios periódicos de sensibilidad antibiótica en nuestro medio, puesto que el comportamiento de en nuesterias son los mecanismos de res y las regiones (tal como lo variables en el tiempo trabajo), para asi tratar de determinar el intervalo de tiempo en el que las bacterias desarrollen resistencia a un determinado antibiótico.

6. Desarrollar estudios prospectivos de ensayos terapéuticos y valorar la sensibilidad de los antibióticos terapentio.

7. Realizar estudios de resistencia cruzada entre los diferentes grupos de antibióticos, ya que nuestro estudio rentes si hubo el antecedente de uso previo de Eritromicina si hubo el antecedente de uso pro

8. Agregar terapia antiseborreica como coadyuvante al tratamiento antibiótico, para evitar la progresión de cuadro a estados más severo.

BIBLIOGRAFIA
1. ACOSTA, J.; CABRERA, N.; TEJAS, I.. Efecto de una politica de control de antimicrobianos en la susceptibilidad de los microorganismos. Vol. 3, No. 4 Mayo 27,1998 ís

2. ALBESI, A. Capa Cornea, humer

Act. Terap. Dermatol. 1994: A: SANCHEZ, J. Guia Práctica Actualizada del Uso de Roaccutan. Permanyer Publications. Aarcelona. España. 2000. P.p. 7-9; 17-29.

ATLAS, RM. Principles of Microbiology. Ed Mosby First edition. St Louis Missouri. 1995.

CABALLERO, A. Metodologia de la Investigación Cientifica. Edit. Técnico Cientifica S.A. $1^{q}$ edición. Lima Perú. 1987. P.p. 98-120. . CANALES. B. Metodologia de

Thauras. P. A. Boletin De Alan \& Johnson. Brasil. 1989. P.p. 11 - 16 .

meopatia. Pevista eletrónica y Homeopatia. A

Medspain ht1p:I WWw w. medspain.comativas terapéuticas en el DERMALUX AV.. Nuevas alternativas

tratamiento del Acné. Revista electronica. DOMINGUEZ, L.: SAUL, A. Programa de. Acné Vulgar y Juvenil. para Medicos Gédica Continua. $1^{9}$ edición. 1996. México. Libro 4. PP. 3-6.

11. DRENO, B.: REYNAUD, A.; MOYSE, D. Erythromicin - resistance of cutaneous bacterial flora in acne. European Journal of Dermatology. Vol 11. Issue 6. Nov. - Dec. 2001.549 J3.

12. FALABELLA, R.; ESCOBAR, C. DE

edición. 1998. Colombia. P.p. $41-47$. 13. FARRERAS, P; ROZMAN, C. Medicina Interna. Edit. Mosby Doyma. $13^{\circ}$ edición. 1995. España. Wolum, K. Dermatologia en
14. FITZPATRICK. T.B.; EISEN, A; WOLFF, K.
Medicina General. Edit. Médica Panamericana. $4^{\circ}$ edición. 199\% 源 GONZALEZ, A. Medicina Cutanea.

16. HERANE H. M I Estudio abierto de evaluación de la eficacia clínica y tolerancia de Adapaleno gel al $0,1 \%$. Rev. Chilena Dermatol. 1998: 14(4).

17. HERANE H., M. L. Acne severo, clinica y patogenia. Rev. Chilen Dermatol. 1997: 13(2).

Electos adversos de la terapia antiacnè. Rev. Chilena Dermatol. 1996: 12(2)

19. HIOK, T.; YEO, M. C. TAN, M. L. Antibiotic Sensitivity of Propionibacterium acnes in Patients with Acne Vulgaris in a Tertiary Dermatological Referral Center in Singapore. Annals Academy of med org'pdt 0101/tanhin.pdf

20. INSALUD. Boletín Intormativo de Servicios Farmacéuticos del Insalud de Cantabria. Uso de agentes sistemicos en el acnè vulgar. Am Fam Physician 2000; 62: 1823.30, 1835.6 www.humv.es/unciones/servicios/centrates S. Antimicrobial S

21. KURUKAWA, ., NISHIJMAA, C., KANA ceptibility of Propionibacterium acnes isolated from Acne vulgaris. European Journal of Dermatology. Vol. 9 issue . gel and once-daily applications of Adapalene $0,1 \%$ gel: a andomized trial. Cutis 2001. Jun.; 67 (6 Suppl.) $10-6$

23. LYNCH, M; RAPHAEL, S. Métodos de Laboratorio. Editoria $930-931 ; 978-979$

24. MANDELL, G. L.; BENNET, J. E.; DOLIN, R. Principles and Pracice of Infectious Disea 1994. P.p. 72-73; $121-123 ; 150 ; 192$

26. MIMS, C. A. PLAYFAIR, J. Microbiologia Médica. Editorial Mosby. 1 edición. España. 1995. P.p. 3.28; 28.8 - 28.9

Thicos. Rev. Chilena Dermatol. 1997: $13(3)$

8. MORENO, C.; PLANTE, G.: STENGEL, F. Medical MAG. Acné, unia entermedad con serias implicancias

29. MORMONTOY, W. Elaboración del Protocolo de Investigación. Edit. Boehringer Ingelheim. $1^{\circ}$ edición. Lima Peru. 1993. P.p. 36-78. MURRAY, G. Microbiologia Medica. Edit. El Manual Moded edición Mexico D.F. 1997 P.p. $160-165$; $175-177$; 292 .

1. NORD, C. E. Boletin Informativo. Recomicndan ser cautos en ef uso de antibioticos para fratar aché 32. OLAECHEA, B. Investigacion ciciont. Edit. Instituto de Gastroente.

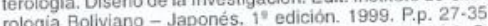

PAREDES, A. Infectologia y Piel. Bacteriologia y Piel. Sociedad Peruana de Dermatología. ${ }^{2}$ edicón. Lima - Penu. 2000. P.p. 11-18. 34. PARSAD, D.; PANDHY, R.; NAGPAL, R. Azithromycin monthly pulse vs daily Docycycline in the tratment of acne vulgaris. Joum put Dermatology 2001 . Jan..2o(1): $1-4$

Edit. Jaime Piquero Martín. $2^{9}$ edición. Bogotá - Colombia. 1995. P.p.11-17; 63-85; 89-95. electrónica. Mny vio com. arłacne

SAMPAIO, S.: RIVITTI, E. A. Dermatologia. Editora Artes Medicas. 1 edición. Sâo Paulo - Brasil. 1998. P.p. 291 - 3016

39. SANCHEZ, H: REYES, C. Metodologia y Diseños en la Investigación Cientitica.

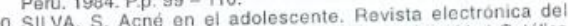
Departamento de Dermatologia. Pontificia Universidad Catolica de Chile. Módulo 3 Lección 11 .

http:Www.escuela.med.puc.citrops/

41. STENGEL, F.; PLANTE, G.; CALIGARIS, V. Medical MAG. Acné. comedogénesis y algo más. Edit. PLM S.A. Peru. Vol. 2. N-12.
Feb. 1997. P.p. 7 - 11. 42. TELLO, J. G.; MALDONADO, O. L. Guía para Proyectos de Investigación Educacional. 12.72

VANDEPITIE, J.; ENGBAEK, K. Métodos Básicos de Laboratorio en Bacteriologia Clinica, Edit. OMS. Ginebra, Suiza. 1993.

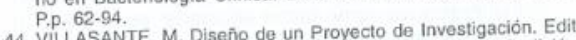
VILLASANTE, M. DIseño Ue un ridad y Región- IIUR. $2^{p}$ edición. Cusco Perú, 1996. P. . $36-45$

45. VIZCARAA. Elementos de investigación. Edit. INIDE. 1

edición Lima. Perú, 1985, Pp. $47-57$.

46. YAMANE. T. Estadistica. Editorial Harla S.A. $3^{\circ}$ edición. México 1979. P.p. $92-99$. 